\title{
The Undergraduate Research Scholarship Scheme: a co-created approach to transforming student learning
}

\author{
Ruth Ayres \\ University of Derby \\ Christopher Wilson \\ Aston University

\section{Introduction}

The value of student as researcher/'co-producer' has been well documented in the research literature: benefits to students engaging in this approach include the development of concrete subject knowledge and such wider transferable skills as team-working, leadership or presentation skills (Carter et al., 2015). There is good evidence of the correlation of research activity and high impact learning (Zimbardi and Myatt, 2012) and clear recognition of the value of situating students as co-producers of research and minimising the tendency towards division of roles between tutor and student (Hoskins, 2015). At a broader graduate level, knowledge and skills associated with research and enquiry are becoming more highly sought as graduate attributes (WEF, 2015; CBI, 2016). At a national level in the UK, the recently-introduced Teaching Excellence and Student Outcomes Framework (TEF) explicitly states that, to meet the 'Gold' TEF Descriptor, "Students are consistently and frequently engaged with developments from the forefront of research, scholarship or practice, and are consistently and frequently involved in these activities" (DfE, 2017). Similarly, student research aligns well with the Research Excellence Framework (REF), where the impact of research on the taught curriculum is growing in importance.

This case study focuses on a 'student as researcher' initiative that was established at the University of Derby in 2013/14, namely Derby's 'Undergraduate Research Scholarship Scheme' (URSS), which provides funded opportunities for students completing Level 5 studies to undertake a real, live research brief in collaboration with a member of academic staff. Over the four years of operation, the scheme has supported 141 projects across a wide range of disciplines. Outlining the key features of the scheme (including its implementation and operation), this paper reflects on the value of URSS as reported by the students who engaged with the scheme and by their supervisors.

Despite sustained advocacy for a shift away from notions of students as passive recipients of the research expertise of the academic community and towards students as active participants in a shared research culture (Healey and Jenkins, 2009), there is a tendency for research hierarchies to be slow to adapt in universities; 'research' remains a predominantly academic staff activity, whilst undergraduate students engage with 'coursework' or 'projects' based on simulation (Bowers and Parameswaran, 2013). Citing Brew (2006, p. 52), Healey et al. (2014) highlight many factors that can keep students 'at arm's length' from university research, particularly in college-based higher education (HE) contexts. They also acknowledge the wider debate about the inter-relationship between teaching and research. Serious research ethics and efficacy issues, often driven by very practical and professional considerations - notably in health disciplines (Wintrup, 2014) - can prevent more immersive research experience during the early stages of undergraduate study. Nevertheless, conceptions of academic levels enshrined in, for example, the UK Quality Code Part A: 


\section{Case Studies}

Setting and Maintaining Academic Standards (QAA, 2014), also establish, across many disciplines, wider expectations relating to undergraduate student research that can delay the development of original research (including primary, empirical research) until the later stages of undergraduate study.

\section{What is the Undergraduate Research Scholarship Scheme (URSS) at Derby?}

The URSS was established at the University of Derby in 2013/14 to enable students successfully completing the second year of their undergraduate study (Level 5) to engage actively with primary research as co-producers - with academic staff - through a cocurricular approach. Drawing from the work of Griffiths (2004), Barnett (2005), Healey and Jenkins (2009) and Ackrill (2015), URSS was established to support research-based, research-led, research-informed and research-orientated activity (Figure 1.) and any reasonable combination of these activities or foci.

\section{RESEARCH ACTIVE}

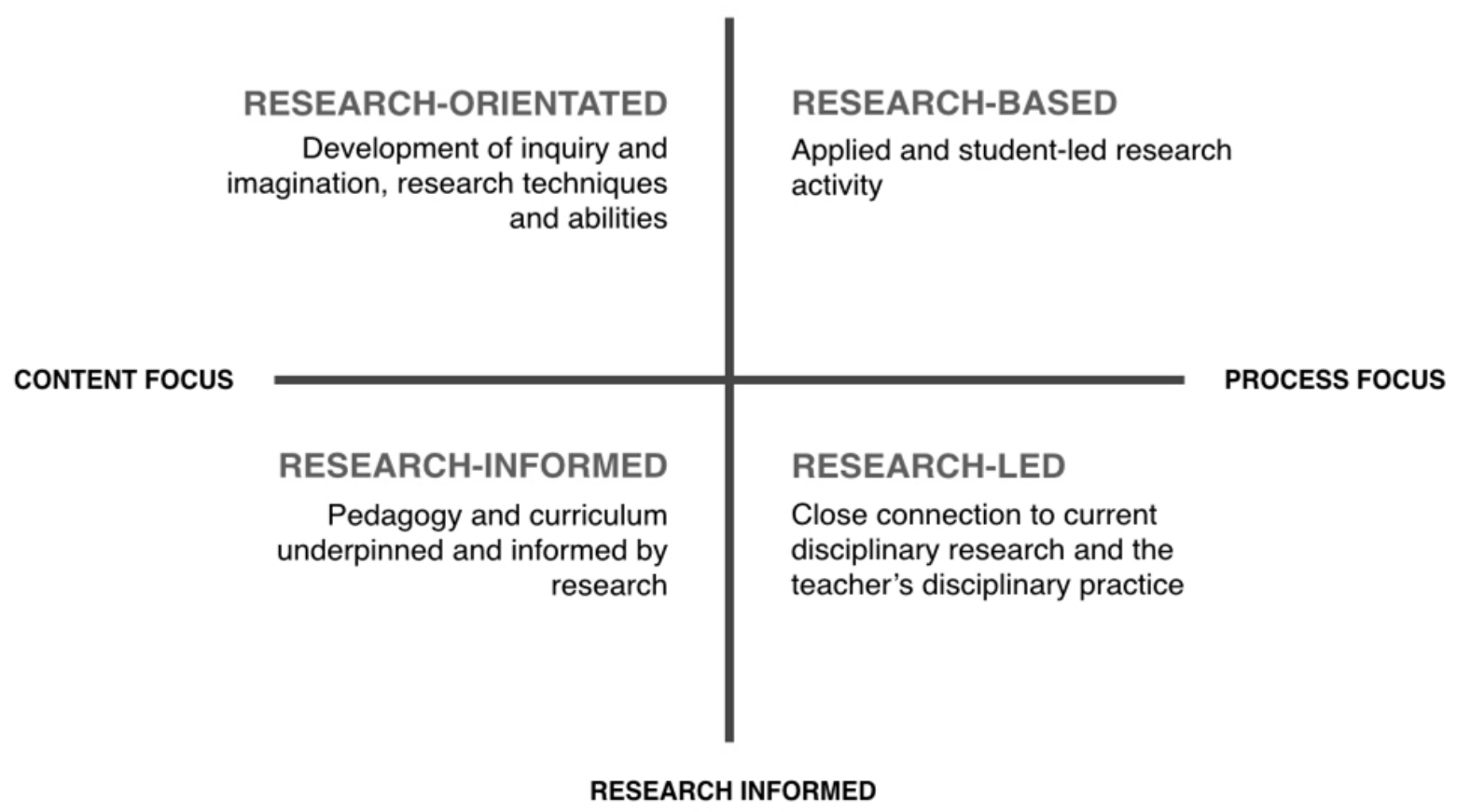

Figure 1. A typology of research-based pedagogies ${ }^{1}$

The key aims of URSS were for students:

1. to gain experience in academic research, contributing new knowledge to their chosen research field;

2. to explore what it is like to work as a member of a research team;

3. to enhance their disciplinary knowledge and subject-specific research skills;

4. to develop generic research and employability skills (e.g. project management, teamworking skills, independent learning, creativity and communication skills);

\footnotetext{
${ }^{1}$ Adapted from Ackrill (2015) and Healey and Jenkins (2009). Reflects Griffiths' (2004) original 'led', 'orientated', and 'based'. Later updated by Healey (2005, in Barnett), to add 'research tutored'.
} 


\section{Case Studies}

5. to enhance their employability prospects through recognition of successful completion of the scheme on their Higher Education Achievement Reports (HEARs).

\section{Implementation of the URSS}

Level 5 students undertake a piece of original research, in the form of a small-scale PhD project which runs over a period of six to eight weeks when conducted full time, or is spread over a longer timescale when undertaken in the part-time mode. The research topic is initiated by the student herself/himself, a project supervisor or both the student and the staff member together. Successful student applicants are given a bursary while participating in the scheme, together with some capital funding to support travel and consumables, as appropriate to the project. All students are required to present their findings at the University's Annual Learning and Teaching Conference (ALTC) by means of a research poster, as well as to contribute, usually with their project supervisors, to the dissemination of their research through external, discipline-based conferences, exhibitions and events and peer-reviewed publications. In 2017 , students were additionally given the opportunity to deliver a full conference presentation at the University's ALTC.

Whilst the scheme has been enhanced each year, the essential process has remained the same (Figure 2.):

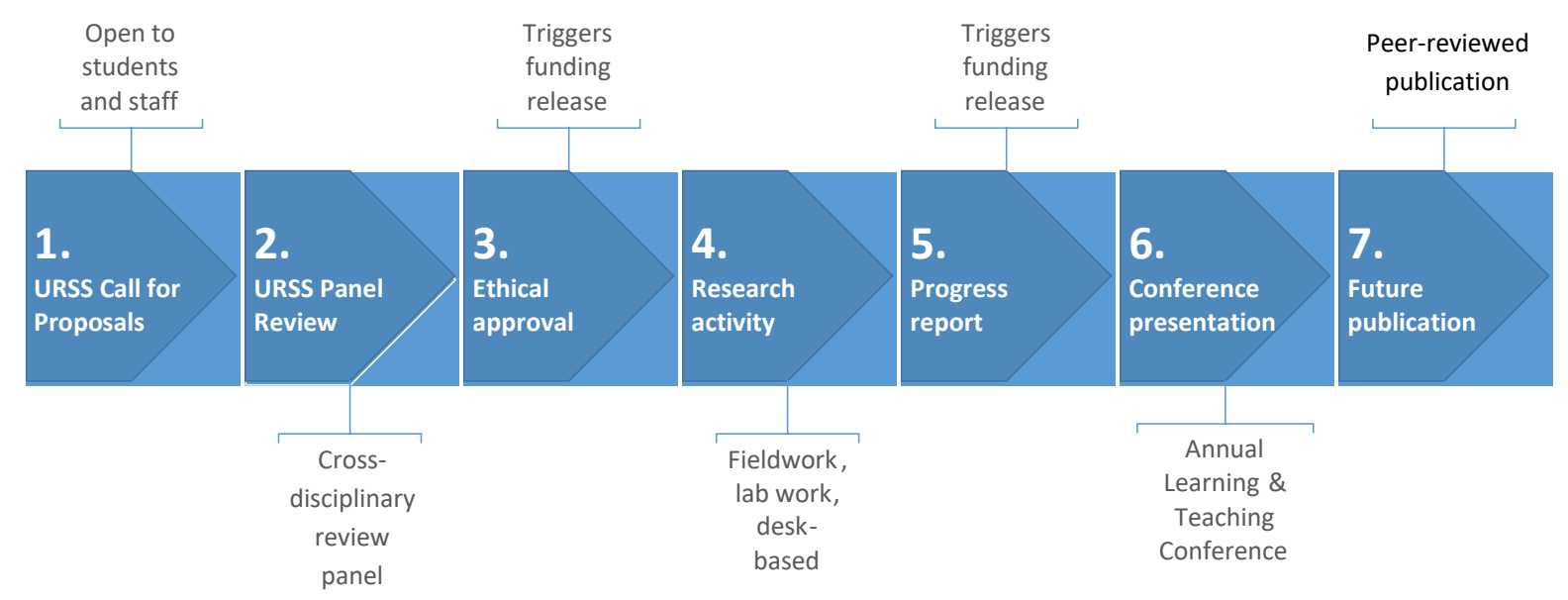

Figure 2. Outline of the URSS Seven-stage process

\section{The key stages of URSS operate as follows:}

\section{URSS Call for proposals}

The scheme is launched annually and promoted in partnership with the Students' Union and academic staff who have been previously engaged with the scheme. Marketing has included poster campaigns, profile-raising events in the University's central student space, involving academic supervisors and students who have participated in URSS in previous years, and promotion by academic staff during their teaching sessions. In addition, information has been provided on the University's website and via social media. Those interested in the scheme are required to complete a simple, standard application proforma, highlighting aims, objectives and rationale for the project. Applicants must also provide the proposed research 


\section{Case Studies}

methodology, ethical considerations and, most importantly, the intended benefits for the student and proposed dissemination route/s for their research outputs.

\section{URSS Panel review}

Applications were considered through a full, peer-review process, which included research leads from all discipline areas. Applications were considered against a set of standard criteria developed and approved by this cross-disciplinary review panel.

\section{Ethical approval}

In line with research governance at the University, all successful URSS applications required ethical approval in line with the appropriate disciplinary requirements before funding was approved and research activity commenced.

\section{Research activity}

Whilst the overall level of funding notionally equated to six to eight weeks of full-time research activity, the period during which this could be undertaken varied according to the nature of the project and students' individual circumstances. In general, projects tended to run between April and June, enabling students to work incrementally, developing aspects of their URSS projects alongside their wider undergraduate studies. In other cases, students' preferences or the nature of the research were such that the URSS projects were undertaken in a more intensive period of time during May and June, after coursework and examinations had been completed.

\section{Progress report}

In order to ensure that project supervision was working effectively and that students were making the required level of progress with their research, a Progress Report had to be completed by all staff and students at the half-way point of the scheme. Satisfactory completion of this report was needed in order to release the second half of the student research bursary.

\section{Conference presentation}

A condition of funding for the scheme was for each URSS student to produce a research conference poster for presentation at the University's ALTC. Academic staff from across the University and its partner organisations attend this event each year and question the students about their research; thus, students become partners in the academic community. URSS tutors prepare students for their contributions to this conference by providing advice and guidance on presentation skills, putting together research posters and communicating research outputs to a wider, academic community. 


\section{Case Studies}

\section{Future publication}

One of the drivers for this scheme was to enable co-creation of research. Some URSS students have gone on to write peer-reviewed manuscripts with their supervisors and copresented their research at external conferences, exhibitions and events.

\section{What level of engagement has there been with URSS?}

Table 1 summarises the number of research proposals made to the URSS since its launch in 2013/14. 141 URSS projects in total have been undertaken over the last four years, with a significant increase in the number of student-led research proposals received over the last two years. This indicates a growing interest amongst the student body in the scheme, together with increased student confidence in putting together their own proposals.

\begin{tabular}{|c|c|c|c|c|c|}
\hline Academic Year & $\begin{array}{c}\text { Student - led } \\
\text { research } \\
\text { proposals }\end{array}$ & $\begin{array}{c}\text { Staff - led } \\
\text { research } \\
\text { proposals }\end{array}$ & $\begin{array}{c}\text { Joint staff }- \\
\text { student } \\
\text { research } \\
\text { proposals }\end{array}$ & $\begin{array}{c}\text { Total number of } \\
\text { research } \\
\text { proposals }\end{array}$ & $\begin{array}{c}\text { Total number of } \\
\text { awards }\end{array}$ \\
\hline $\mathbf{2 0 1 3 / 1 4}$ & 0 & 32 & 4 & 36 & $\mathbf{2 7}$ \\
\hline $\mathbf{2 0 1 4 / 1 5}$ & 2 & 49 & 0 & 51 & 36 \\
\hline $\mathbf{2 0 1 5 / 1 6}$ & 17 & 42 & 3 & 62 & $\mathbf{3 0}$ \\
\hline $\mathbf{2 0 1 6 / 1 7}$ & 31 & 28 & $\mathrm{n} / \mathrm{a}$ & 59 & $\mathbf{1 4 1}$ \\
\hline Scheme Total & $\mathbf{5 0}$ & $\mathbf{1 5 1}$ & $\mathbf{7}$ & $\mathbf{2 0 8}$ & \\
\hline
\end{tabular}

Table 1. The number of applications and awards made to the URSS since its launch in 2013/14

The topics researched for URSS have been broad and far-reaching, spanning a range of different subject areas, as summarised in Table 2. 
Case Studies

\begin{tabular}{|c|c|c|c|c|c|c|c|}
\hline $\begin{array}{c}\text { Academic } \\
\text { Year }\end{array}$ & Arts & $\begin{array}{c}\text { Business, } \\
\text { Law \& } \\
\text { Social } \\
\text { Sciences }\end{array}$ & Science & $\begin{array}{c}\text { Engineering, } \\
\text { Computing \& } \\
\text { Mathematics }\end{array}$ & Humanities & Education & Other $^{2}$ \\
\hline $\mathbf{2 0 1 3 / 1 4}$ & 1 & 5 & 12 & 6 & 1 & 1 & 1 \\
\hline $\mathbf{2 0 1 4 / 1 5}$ & 4 & 4 & 20 & 5 & - & - & 5 \\
\hline $\mathbf{2 0 1 5 / 1 6}$ & 1 & 9 & 10 & 4 & 2 & 3 & 7 \\
\hline $\mathbf{2 0 1 6 / 1 7}$ & 2 & 13 & 15 & 4 & 1 & 5 & - \\
\hline Totals & $\mathbf{8}$ & $\mathbf{3 1}$ & $\mathbf{5 7}$ & $\mathbf{1 9}$ & $\mathbf{4}$ & $\mathbf{9}$ & $\mathbf{1 3}$ \\
\hline
\end{tabular}

Table 2. Subject disciplines in which URSS projects have been undertaken

\section{What has been the impact of URSS for staff and students who participated in the scheme?}

Recognising the self-selection involved in the case of those students who elect to participate in URSS, and the limitations associated with self-report surveys in determining measurable gains in related skills and capabilities (Linn et al., 2015), we have drawn together some preliminary findings from surveys and interviews with staff and students who participated in the URSS. Individuals were surveyed on what they felt they had gained from the scheme.

Taking together survey data from the last two years, $49 \%$ of all respondents confirmed that work undertaken through URSS had contributed to research publications; $23 \%$ of all respondents commented that they had presented their research outcomes at an external conference.

Student-respondent data from the last two years reveals that $64 \%$ felt that URSS had prepared them well for their final-year Independent Study projects. For example:

"I feel I have more confidence in my ability to design an appropriate experiment, this has helped me with my Independent Study project, and also calms my nerves about having to conduct research at postgraduate level, which is where I aim to go next."

$69 \%$ of student respondents said that their experience with URSS had influenced their decision regarding future study or research. Comments included:

"Gave me the insight of the essence of research - experiencing what a path into academia would be like, or what's expected in a research role"

2 'Other' includes projects from specialist units within the University, such as the International Centre for Guidance Studies (iCeGS); and the University's Online Learning Department and Joint Honours Scheme. 


\section{Case Studies}

"It has also opened my eyes to a career in research. It has subsequently allowed me to get involved in submitting a journal article."

All but one of the student respondents said they would recommend applying to URSS to other students; qualitative comments referenced the development of a range of valuable transferable skills, including, in particular, team-working and networking skills. Typical comments include:

"The URSS is a fantastic opportunity for students to research a topic of interest, resulting in the acquisition of a vast array of skills, some of which include: critical thinking, problem-solving and decision-making."

"I gained skills within researching, writing and presenting work in correct formats, how to convert data into a visual aid and how to present work to other scholars."

Students placed greatest value on the opportunity they were given through the scheme to undertake real, live research, noting for example:

"It was a great experience that gave an insight into the world of research. Up to this point my university career has been very theoretical and classroom based."

"Great experience to work on real research with a professional research team."

From a staff perspective, the scheme provides valuable support for early career researchers as they embark upon building a research profile, acting as a pipeline for identifying potential future postgraduate research talent. Comments from staff who have supervised students on the scheme included:

"I think this is an excellent scheme... which will hopefully build the research capacity of students and staff. I hope that I will be able to recruit my student once she has finished her degree. We really valued her contribution to our work."

"The research has provided a starting point for further study for both the students and supervisors. The project is an excellent opportunity for students and enhances their CVs."

"It might allow a staff member to collect valuable pilot data for an idea, research project, grant or potential collaboration. Alternatively, it might allow for a staff member to increase their research impact means."

"My student was a great help - enabled me to do research that I did not have time for."

"This has enabled the project to make significantly more progress than would have been the case without URSS input."

Reflecting upon our experience of running the URSS over the last four years, we have highlighted four areas that we feel are pertinent to others who may be considering developing a similar scheme: 


\section{Case Studies}

\section{The experience can be transformational for students}

Since launching the scheme, there has been growing interest in participation amongst the student body, with some students thrilled by the opportunity to explore (with academic support), an area of research that they are passionate about outside their normal taught curriculum. Others are keen to take forward areas of interest from within their degree programmes. Students presenting their research findings at the ALTC were all enthusiastic about the journeys they had undertaken and the transformational impact of the scheme on their personal development. Almost all were keen to take their projects forward and pursue further research opportunities. The pedagogic value of enabling students to research an area of personal interest led to deep learning and the development and enhancement of a range of transferable skills, valuable for future employment or further study.

\section{The challenge for students can be considerable}

For many students, URSS projects can be considerably challenging experiences. Most have never undertaken research activity of such intensity and duration and some find the process of research quite lonely, particularly in the desk-based projects. As this is often the first time that students have presented beyond their own cohorts, the leaders of the scheme, together with the academic supervisors, provide a support package that, as noted earlier, builds confidence amongst the students and develops their communication skills.

\section{There's never a good time to launch the scheme}

There is no 'perfect' time to launch the scheme. Whilst students have prolonged periods away from timetabled teaching activity during the year, professional commitments for academic staff increasingly extend throughout the entire calendar year. Projects need to have tangible research outputs for presentation at the University's ALTC in July and work has to be completed during those times when, in the case of students living away from home, they are in their student accommodation. As mentioned earlier, the exact nature of the project and students' individual circumstances dictate when the work (e.g. field work and projects linked to planned exhibitions and events) can be undertaken and determine whether it is feasible to spread the research across the year or undertake it within a shorter, more intensive period of time. The scheme aims to provide full equality of opportunity and it has achieved a good gender balance over the years. The student bursary enabled many students otherwise needing to undertake part-time work during non-teaching periods of the academic year to engage with URSS. Equally, many busy academic staff have been able to make further progress with their research projects, and at a faster rate through URSS than would otherwise have been possible.

\section{Communicate, communicate, communicate}

The more varied and frequent the communication about the scheme the better, to enable the greatest reach of information to all staff and students. Over the years, the URSS has been advertised through a variety of means, as already indicated. The challenge for any cocurricular activity to maintain visibility is considerable and should not be underestimated. 


\section{Case Studies}

\section{Conclusions and next steps}

Whilst effective evaluation of the impact of co-curricular initiatives is notoriously difficult, the URSS has proved a valuable mechanism for bringing together academic staff and undergraduate students in the co-creation of knowledge. The URSS comes at a significant financial cost to the institution, but this paper has highlighted three key positive outcomes from the scheme:

1. The effective development and enhancement of students' disciplinary knowledge and research and transferable skills;

2. The opportunity to build institutional research capacity and capability, particularly amongst early career researchers;

3. The opening of opportunities for inter-disciplinary projects, through the bringing together of different perspectives from a range of disparate research fields.

Further evaluative work is planned for the scheme, but ultimately it is the responsibility of individual Higher Education Providers to determine how they distribute resources and what mechanisms are necessary to evaluate impact and return on investment. As individuals continue to invest heavily in their HE experience, there is an ever-growing need for such initiatives as URSS: they promote and enable independent, personalised learning, which in turn prepares students well for lifelong learning and their future employment.

\section{Reference list}

Ackrill, R. (2015) Research-informed teaching and curriculum design on an Applied Economics module: an exercise in constructive alignment. York: The Higher Education Academy. Available at: https://www.heacademy.ac.uk/knowledge-hub/research-informedteaching-and-curriculum-design-applied-economics-module-exercise (Accessed: 20 February 2017).

Association of Graduate Recruiters (2016) AGR Annual Survey. Available at: https://www.justoncampus.co.uk/wp-content/uploads/2016-AGR-Annual-Survey-2.pdf (Accessed: 20 February 2017).

Barnett, R. (ed.) (2005) Reshaping the University: New Relationships between Research, Scholarship and Teaching. Maidenhead: McGraw Hill / Open University Press, 67-78.

Bowers, J. and Parameswaran, A. (2013) 'Differentiating undergraduate research.' Teaching in Higher Education, 18(5), 453-464. Taylor and Francis. Available at:

http://dx.doi.org/10.1080/13562517.2012.752731 (Accessed: 14 March 2017).

Carter, D.F., Ro, H.K., Alcott, B. and Lattuca, L.R. (2015) 'Co-Curricular Connections: The Role of Undergraduate Research Experiences in Promoting Engineering Students' Communication, Teamwork, and Leadership Skills.' Research in Higher Education, 57(3), 363-393. Springer. Available at: http://link.springer.com/10.1007/s11162-015-93867 (Accessed: 20 February 2017).

CBI/Pearson. (2016) The Right Combination: Education and Skills Survey 2016. Available at: http://www.cbi.org.uk/cbi-prod/assets/File/pdf/cbi-education-and-skillssurvey2016.pdf?mc cid=dce980549f\&mc eid=6be1e9feb5 (Accessed: 20 February 2017). 


\section{Case Studies}

Department for Education (2017) Teaching Excellence and Student Outcomes Framework Specification. Available at:

https://www.gov.uk/government/uploads/system/uploads/attachment data/file/658490/Teach ing Excellence and Student Outcomes Framework Specification.pdf (Accessed: 12 November 2017).

Griffiths, R. (2004) 'Knowledge production and the research-teaching nexus: the case of the built environment disciplines.' Studies in Higher Education, 29(6),169-189. Available at: https://doi.org/10.1080/0307507042000287212 (Accessed: 12 November 2017).

Healey, M., Jenkins, A. and Lea, J. (2014) Developing research-based curricula in collegebased higher education. The Higher Education Academy. Available at: https://www.heacademy.ac.uk/system/files/resources/developing researchbased curricula in cbhe 14.pdf (Accessed: 20 February 2017).

Healey, M. and Jenkins, A. (2009) Developing undergraduate research and enquiry. The Higher Education Academy. Available at:

https://www.heacademy.ac.uk/node/3146 (Accessed: 20 February 2017).

Hoskins, S. (2015) Research-based learning, taking it a step further. The Higher Education Academy, Innovative Pedagogies Series. Available at:

https://www.heacademy.ac.uk/system/files/sherria hoskins final.pdf (Accessed: 20 February 2017).

Knight, R-A. and Botting, N. (2016) 'Organising undergraduate research projects: student-led and academic led models.' Journal of Applied Research in Higher Education, 8(4), 455-468.

Linn, M.C., Palmer, E., Baranger, A., Gerard, E. and Stone, E. (2015) 'Undergraduate research experiences: Impacts and opportunities.' Journal of Science, 347,(6222): 1261757. Available at: https://www.ncbi.nlm.nih.gov/pubmed/25657254h (Accessed: 20 February 2017).

QAA. (2014) UK Quality Code for Higher Education Part A: Setting and Maintaining Academic Standards. PART A - The Frameworks for Higher Education Qualifications of UK Degree-Awarding Bodies. Available at:

http://www.qaa.ac.uk/en/Publications/Documents/qualifications-frameworks.pdf (Accessed: 10 November 2016).

Walkington, H. (2015) Students as researchers: Undergraduate research in the disciplines in higher education. The Higher Education Academy. Available at:

https://www.heacademy.ac.uk/system/files/resources/walkington-students-as-

researchers.pdf (Accessed: 16 February 2017).

Wintrup, J. (2017) 'The undergraduate research as co-creation: can we describe new forms of learning gain?' Journal of Educational Innovation, Partnership and Change, 3(1), 2017. Available at:

https://journals.gre.ac.uk/index.php/studentchangeagents/article/download/687/pdf

(Accessed: 12 November 2017). 
Case Studies

World Economic Forum. (2015) The Future of Jobs. Available at:

http://www3.weforum.org/docs/WEF Future of Jobs.pdf (Accessed: 20 February 2017).

Zimbardi, K. and Myatt, P. (2012) 'Embedding undergraduate research experiences within the curriculum: a cross-disciplinary study of the key characteristics guiding implementation.' Studies in Higher Education, 39(2), 233-250. Available at:

https://doi.org/10.1080/03075079.2011.651448 (Accessed: 20 February 2017). 